\section{P-179 COORDINATED END OF LIFE CARE (EOLC) FOR BIRMINGHAM AND SOLIHULL (BSOL) WORKING PARTY}

Debbie Talbot, Tina Swani. Birmingham St Mary's Hospice, Birmingham, UK

\subsection{6/bmjspcare-2018-hospiceabs.204}

In September 2017 we called together individuals from across the city, who are currently delivering or receiving end of life care services. Discussion ensued about how services could be improved. All agreed to collaborate to develop a more coordinated approach. The working party membership developed a clear vision and associated mission statements, as well as an outline plan for a new system wide model of coordinated care delivery.

Vision To create a better experience at the end of life (EOL) for everyone in Birmingham and Solihull.

Mission statements By bringing together providers with a common purpose, to shape EOL service development and improvement we will:

- Create a central coordination system for all EOL services that will ensure:

- Early identification of those in need of end of life care

- Improved patient-centred care, designed according to individuals' priorities, including promoting choice of place of care and reducing inappropriate hospital admissions

- Equitable access to services

- Fewer gaps in care provision

- Increased information sharing to enhance patient safety.

- Promote a compassionate community ethos, working with the diverse communities in BSOL to design and deliver end of life care

- Ensure end of life education is delivered in a coordinated way, to best enable everyone to care

- Collaborate to design services that are delivered efficiently and are sustainable by sharing intelligence, eliminating duplication of provision and holding each other to account

- Evaluate evidence concerning new models of care critically to inform the activities of the Working Group

- Undertake evaluation research to determine the impact of the new BSOL end of life care system/model.

Achievements The Vision and mission statements have been integrated into a re-draft of the Birmingham and Solihull Sustainability and Transformation Partnership Strategy, as new priorities for end of life care. The working party will be represented at an STP EOLC oversight group, which will drive the implementation of these priorities and will report into the STP portfolio board.

\section{P-180 FINALLY, FULLY, FUSED!: THE END OF THE LONG ROAD TO COMPLETE SPECIALIST PALLIATIVE CARE SERVICES INTEGRATION}

Karen Groves, Helen Birch. Queenscourt Hospice, Southport, UK

10.1136/bmjspcare-2018-hospiceabs.205

Background Specialist palliative care services (SPCS) often develop within organisations providing care in community, hospital and hospice. Even in their own geographical area, patients may meet at least three separate specialist teams - all working slightly differently, with individual telephone numbers and sets of guidelines - in addition to tertiary centre specialist teams.

Aim To provide a single, seamless, SPCS for patients, families and their associated health professionals.

Method A recent community services tendering process had threatened to destroy at a stroke, a successful, longstanding plan to keep community and hospital SPCS integrated through five local health service reorganisations/TUPE transfers. Negotiation, opportunity and creativity allowed the final pieces of the jigsaw to slot into place. Palliative care nurse specialists (PCNS), admin staff and consultants (NHS contract retained) transferred under TUPE arrangements, enabling the formation of a single integrated SPCS working across all settings.

Results A single telephone numbered, Hospice Central Access Hub, takes all clinical calls from patients registered with the integrated SPCS, their families and health professionals manned 7/7, from 9-5. A full service operates during the week, and a doctor, PCNS, Transform facilitator and admin support share weekend work across all settings. At night clinical calls are directed to the inpatient unit who access the doctor on call if required.

Conclusion Wholly integrated services means patients have ONE - number to ring, team to speak to, joined up service, set of guidelines and bereavement service. The team receive the SAME - development training, uniform, support, and access to assistance. ONE single multidisciplinary team meeting discusses all new referrals to the whole service, documented on ONE single electronic patient record with mobile access for clinical staff with no duplication. There is much to do and many ideas for further development, but with a new improved road to travel.

\section{P-181 INTEGRATED PALLIATIVE AND END OF LIFE CARE ON A SMALL ISLAND}

${ }^{1}$ Anne Mills, ${ }^{1}$ Christine Bloomer, ${ }^{1}$ Giovanna Cruz, ${ }^{1}$ Sarah McGhee, ${ }^{1}$ Gillian Street, ${ }^{2}$ Anne Hendry, ${ }^{2}$ Mandy Andrew. ${ }^{1}$ Hospice Isle of Man, Strang, Isle of Man; ${ }^{2}$ International Centre for Integrated Care, Paisley, UK

\subsection{6/bmjspcare-2018-hospiceabs.206}

Background The integrated care concept is being implemented world-wide but is often considered setting-specific. Small islands are one of these settings which face particular issues. Hospice Isle of Man is taking a measured approach, from which we hope that others might be able to benefit.

Aim To develop a strategy for integrated palliative and end of life care on a small island.

Methods

- Create connections and networks to support the planning, implementation and evaluation stages of the work

- Identify, via a needs assessment, what works, what gaps need filled and what matters to the population and professionals

- Identify particular issues facing small islands and ensure that any recommendations for change lead to solutions which are sustainable in the longer term.

Results to date Hospice Isle of Man formed relationships with the International Foundation for Integrated Care (IFIC) and IFIC Scotland who facilitated two face-to-face stakeholder meetings in 2017 and 2018. Using an example of a patient journey, areas that could be improved were identified. As a result, Hospice Isle of Man, public health care providers and 